\title{
Pendampingan dan Pembuatan Konten Video untuk Mendukung Pemasaran melalui Media Sosial Bagi UMKM Fashion
}

\author{
Yohanes Priadi Wibisono ${ }^{1}$, Clara Hetty Primasari ${ }^{2}$, Danniel Setiawan ${ }^{3}$ \\ ${ }^{1223)}$ Program Studi Sistem Informasi, Universitas Atma Jaya Yogyakarta, Yogyakarta, Indonesia \\ Corresponding Author: Clara Hetty Primasari, clara.hetty@uajy.ac.id
}

\begin{abstract}
Abstrak: Industri fashion merupakan salah satu industri yang memberikan sumbangsih tertinggi dalam perekonomian Indonesia. Berdasarkan data dari CNBC Indonesia pada tahun 2019, industri ini berkontribusi sekitar 18,01\% atau setara dengan 116 triliun Rupiah. Hal ini disebabkan karena meningkatnya jumlah pemain dalam industri fashion Indonesia. Kenaikan ini berdampak pada tingginya tingkat persaingan pada industri tersebut. Persaingan dalam pemasaran produk fashion melalui media social dan marketplace menjadi salah satu tantangan tersendiri bagi para pelaku industri fashion. Hal ini berdampak pada UMKM khususnya di bidang fashion. Mereka membutuhkan konten pemasaran yang lebih menarik. Dari yang sebelumnya berupa foto, menjadi konten video. Dalam pemasaran yang dilakukan, tidak semua UMKM, khususnya Lori Collection, menguasai metode pembuatan konten video yang menarik dan profesional. Berdasarkan situasi dan kondisi di atas, maka disusunlah konsep Pengabdian Masyarakat ini untuk memberi pelatihan dan pembuatan konten video marketing. Hasil dari pengabdian ini adalah video marketing yang dibuat secara professional dan siap untuk diposting di media sosial Lori Collection. Manfaat yang dirasakan oleh Lori Collection antara lain terbangunnya brand image Lori Collection di dunia maya dan kemudahan dalam promosi karena bisa dilakukan di mana dan kapan saja asalkan terhubung dengan internet dan memiliki gadget untuk melakukan pembuatan konten.
\end{abstract}

Kata Kunci: konten video, pemasaran, industry fashion, UMKM

Abstract: The fashion industry is one of the industries that provides the highest contribution to the Indonesian economy. Based on data from CNBC Indonesia in 2019, this industry contributed around $18.01 \%$ or equivalent to 116 trillion Rupiah. This is due to the increasing number of players in the Indonesian fashion industry. This increase has an impact on the high level of competition in the industry. Competition in marketing fashion products through social media and marketplaces is one of the challenges for fashion industry players. This has an impact on MSMEs, especially in the fashion sector. They need a new marketing method from photos to video content. In the marketing that is carried out, not all MSMEs, especially Lori Collection, master the marketing method using video content. Based on the situation and conditions, the concept of Community Service was compiled to provide training and create video marketing content. The result of this dedication is video marketing that is professionally made and ready to be posted on Lori Collection's social media. The benefits felt by Lori Collection include the development of the Lori Collection brand image in cyberspace and the ease of promotion because it can be done anywhere and anytime as long as it is connected to the internet and has a gadget to create content.

Keywords: video content, marketing, fashion industry, MSME

Submitted: 29-03-2021, Revised: 19-04-2021, Accepted: 10.09.2021 


\section{Pendahuluan}

Trend Fashion belakangan ini menjadi industri yang paling menguntungkan dan popular di Indonesia. Berdasarkan data dari CNBC Indonesia pada tahun 2019, perkembangan industri fashion mampu berkontribusi sekitar 18,01\% atau Rp. 116 Triliun (Setiawan dan Sesilia, 2019). Menurut Badan Pusat Statistik, pada 3 bulan pertama tahun 2019, produksi industri fashion tumbuh sebesar 29,19\% (Kementrian Perindustrian, 2019). Selain itu, fashion adalah salah satu tulang punggung ekspor industri ekonomi kreatif. Di banding subsektor lain, ekspor fashion melebihi setengah dari total ekspor secara keseluruhan. Fashion telah berkontribusi sebesar 3.76\% dengan nilai ekspor mencapai 13,29 Milyar Dollar Amerika (Setiawan dan Sesilia, 2019).

Badan Ekonomi Kreatif terus berupaya untuk menguatkan ekosistem serta mendorong pertumbuhan pada sektor ini. Hal ini berdampak pada meningkatnya jumlah pemain dalam industri fashion. Peningkatan jumlah pelaku usaha fashion mengakibatkan semakin tinggi pula tingkat persaingan pada industri tersebut. Tidak terkecuali persaingan pemasaran melalui media sosial dan marketplace. Persaingan dalam pemasaran produk fashion melalui media social dan marketplace menjadi salah satu tantangan tersendiri bagi para pelaku industri fashion Schwarzl and Grabowska, 2015). Kebanyakan teknik marketing masih menerapkan pemasaran dalam bentuk foto atau gambar melalui media socia seperti Instagram dan Facebook (Primasari, dkk., 2020). Beberapa dari UMKM Fashion sendiri sudah mempunyai website resmi, akan tetapi konten yang ditampilkan juga kebanyakan masih berupa foto atau gambar sehingga kesannya masih statis. Jika menggunakan pemasaran yang sama secara terus-menerus tentang memposting gaya informasi yang formatnya serupa, pelanggan mungkin tidak tertarik dan akhirnya melepaskan diri dari merek tersebut. Selain itu pelanggan suka melihat merek yang menarik dan konten segar (Kee and Yazdanifard, 2015).

Konten video menjadi salah satu konten yang banyak dikonsumsi di kalangan pengguna media sosial. Konsumsi video online telah menjadi trend yang meningkat pesat beberapa tahun terakhir (Odden, 2013). Menurut Brown, video merupakan salah satu cara untuk membuat impresi yang kuat tentang suatu produk di benak audiens (Brown, et al., 2005). Konten yang menarik dan solid adalah konten yang berisi tentang bagaimana cara menginformasikan dan membujuk calon pelanggan untuk meningkatkan kesadaran atau mengubah persepsi tentang suatu merek. Konten yang lebih baik dapat memotivasi pelanggan untuk membeli barang atau jasa, dengan begitu, mereka akan menjadi pelanggan setia bahkan mereka dapat menyebarkan kesan yang baik tentang merek tersebut ke orang lain. Pembuatan konten yang menarik untuk mendukung pemasaran juga bertindak sebagai strategi untuk membangun dan mempertahankan hubungan melalui penerbitan konten yang berharga untuk target konsumen. Ini meningkatkan proses pembelian dengan menambahkan suatu kesan unik kepada pelanggan(Jafar and Wahyuni, 2016).

Hard skill merupakan penguasaan dalam bidang ilmu pengetahuan, teknologi dan keterampilan teknis yang berhubungan dengan kegiatan manusia saat ini (Zulkifli, Rasid, Tewal, \& Kojo, 2018). Hard skill erat kaitannya dengan keterampilan teknis yang melekat atau dibutuhkan untuk profesi tertentu (Boman and Raijonkari, 2017). Hard skill adalah salah satu hal yang dibutuhkan dalam membuat konten berupa video. Dalam pemasaran yang dilakukan, tidak semua UMKM khususnya di bidang fashion menguasai metode pemasaran menggunakan konten video. Konten video membutuhkan keahlian dan pengetahuan yang mendalam mengenai pembuatan video. Karena memproduksi video membutuhkan skill dan waktu, proses pembuatannya perlu mengandalkan bantuan dari luar untuk pemasaran video (Irfan, 2013). 
Lori Collection merupakan salah satu UKM yang bergerak di bidang fashion ready-towear yang dirintis oleh Dina Rosaria. Lori memiliki kekhasan yaitu menggunakan tenun lurik sebagai bahan baku utamanya. Tenun lurik dipilih karena selain merupakan produk local dan sarat budaya, tenun lurik juga paling terjangkau harganya untuk dapat dijangkau mayoritas penduduk Indonesia dibandingkan Wastra tradisional lainnya.

Di tengah maraknya bisnis fashion sejenis di Indonesia, Lori hadir dengan konsep yang berbeda. Ciri khas asimetris menjadi karakter produk Lori. Selain tenun lurik, Lori juga mengkreasikan kembali kain perca sisa produksi garmen dan sisa kain dari proses penjahitan. Pemanfaatan ini memberi nilai tambah bagi barang yang sering kali dianggap sebagai limbah industri tersebut. Selain itu, Lori juga mengusung pengemasan zero waste strategy untuk meminimalisasi sisa produksi dan sebagai gantinya, memanfaatkan sisa produksi untuk dijadikan kemasan produk yang cantik dan memiliki nilai tambah.

Media sosial menjadi salah satu media yang efektif untuk beriklan. Hal ini dikarenakan, banyak audiens yang tertarik dan terpengaruh dengan adanya iklan di media sosial (Handoko, dkk., 2019). Saat ini, Lori memiliki 2 orang admin untuk mengelola pemasaran di media sosial seperti WhatsApp, Instagram, Facebook dan Website. Melihat perkembangan media social yang mulai mengarah ke konten video, Lori ditantang untuk mampu beradaptasi terhadap kebutuhan pasar dan pemasaran. Akan tetapi, Lori memiliki keterbatasan pengetahuan dalam pembuatan konten video yang menarik. Padahal untuk menghasilkan konten dengan engagement yang baik, dibutuhkan skill khusus dalam membuat, mengedit, memanipulasi content serta kreatifitas yang tinggi agar dapat menghasilkan content yang menarik. Lori berkeinginan dapat mengembangkan diri dan mampu memproduksi konten video secara mandiri.

Berdasarkan permasalahan Lori mengenai keterbatasan dalam membuat dan mengelola konten video tersebut, maka diusulkan konsep pengabdian berupa pelatihan dan pengembangan pembuatan konten video marketing tersebut. Tujuannya adalah agar Lori Collection dapat meningkatkan kemampuannya dalam pemasaran dan memproduksi konten-konten yang mendukung pemasarannya melalui media social. Diharapkan dengan konten video yang menarik di media social dapat meningkatkan dan menjangkau calon pelanggan baru sehingga dapat meningkatkan penjualannya.

\section{Metodologi}

\section{A. Metode}

Pendekatan yang digunakan sebagai solusi untuk upaya peningkatan engagement atas promosi Lori Collection adalah berupa pendampingan dan pembuatan konten video untuk mendukung pemasaran melalui media sosial. Hal ini didasarkan pada fakta bahwa menonton video dari media online telah menjadi tren atau kebiasaan masyarakat belakangan ini (Odden, 2013). Lebih dari itu, video adalah salah satu cara terbaik untuk membuat kesan yang kuat tentang suatu merek dalam pikiran penonton (Brown, et al., 2005). Lori Collection sebagai mitra, berperan sebagai penyedia data yang dibutuhkan dan juga yang akan didampingi dalam pembuatan konten. Pengumpulan data akan dilakukan dengan model wawancara dan diskusi. Kebutuhan data akan digunakan untuk pembuatan konten agar sesuai dengan keinginan dan kebutuhan mitra. Setelah pembuatan konten selesai, akan dilakukan pendampingan pelatihan agar mitra dapat menggunakan sistem secara mandiri. Materi pendampingan meliputi:

1. Penggunaan tools dalam pembuatan konten Video.

2. Pemasaran produk dengan menggunakan konten video melalui media sosial. 


\section{B. Tahapan dan Luaran Kegiatan}

Pelaksanaan kegiatan Pengabdian Masyarakat ini dibagi ke dalam 3 tahap yaitu tahap Persiapan, tahap Pelaksanaan, dan tahap Pelaporan. Rincian kegiatan dan luarnya dapat dilihat di Tabel 1.

Tabel 1. Tahapan dan Luaran Kegiatan

\begin{tabular}{|c|c|c|}
\hline No & Kegiatan & Luaran \\
\hline & Tahap Persiapan & \\
\hline 1. & Menyiapkan Rencana Kerja secara detail & Dokumen Rencana Kerja \\
\hline 2. & $\begin{array}{l}\text { Mempersiapkan materi untuk pengumpulan } \\
\text { data }\end{array}$ & $\begin{array}{lll}\begin{array}{l}\text { Dokumen materi informasi yang akan } \\
\text { didapatkan dari mitra }\end{array} & \\
\end{array}$ \\
\hline \multirow[t]{2}{*}{3.} & $\begin{array}{l}\text { Mempersiapkan materi-materi untuk pelatihan } \\
\text { setelah konten selesai dibuat }\end{array}$ & Materi pelatihan \\
\hline & Tahap Pelaksanaan & \\
\hline 4. & Pembuatan konten video marketing & Konten video marketing \\
\hline 5. & Melakukan evaluasi konten video & Hasil evaluasi konten video \\
\hline \multirow[t]{2}{*}{6} & $\begin{array}{l}\text { Memberikan pelatihan ke mitra tentang } \\
\text { pembuatan konten video }\end{array}$ & $\begin{array}{l}\text { Pengetahuan mengenai membuatan konten } \\
\text { video marketing }\end{array}$ \\
\hline & Tahap Pelaporan & \\
\hline 6. & Penyusunan Laporan Akhir & Laporan PPM final \\
\hline 7. & Membuat artikel untuk publikasi & Artikel jurnal \\
\hline
\end{tabular}

\section{Hasil dan Pembahasan}

Sasaran untuk kegiatan Pengabdian Masyarakat ini adalah UMKM di Yogyakarta. Mitra yang dipilih adalah Lori Collection. Kegiatan Pengabdian ini dibagi menjadi tiga tahapan, yaitu tahap persiapan, pelaksanaan, dan pelaporan. Pada tahapan persiapan yang dilakukan adalah menyiapkan rancangan kerja yang detail, mempersiapkan konsep pemasaran, dan mempersiapkan alat-alat multimedia untuk penyuntingan video. Pada saat persiapan, berdasarkan hasil observasi dan wawancara yang dilakukan terhadap UMKM Lori Collection, ditemukan keterbatasan Hard Skill yang dimiliki oleh UMKM dalam memanfaatkan konten video untuk memasarkan produknya. Kondisi tersebut menjadikan tidak ada peningkatan yang lebih baik terhadap kondisi pemasaran yang selama ini digunakan. Hal ini juga memberikan dampak terhadap ketidakmampuan UMKM dalam memperluas pemasarannya. berikut:

Kegiatan yang dilaksanakan pada tahap pelaksanaan kegiatan pengabdian adalah sebagai

\section{PRA PRODUKSI}

Pembuatan Konsep, Pembuatan Alur Cerita, Pembuatan Story Board, List Alat Multimedia yang akan digunakan dalam pembuatan konten video.

\section{PRODUKSI}

Pengambilan video dilaksanakan pada hari Jumat,14 Oktober 2020 di Waroeng Tedoeh. Sebelum pengamblian video Lori mempersiapkan produk baju yang hendak ditampilkan pada video profile. Tim pengabdian melihat sekeliling kawasan tersebut untuk menentukan daerah mana yang cocok untuk pembuatan video profile. Pada hari $\mathrm{H}$, Tim melakukan briefing kepada model supaya konsep video berjalan sesuai skenario yang telah direncanakan. Selanjutnya dilakukan pengambilan video. Hal yang pertama dilakukan adalah mengatur kamera ke resolusi 1080 atau FHD, kemudian exposure dengan ketentuan Shutter Speed harus berada di 1/100 1/120 untuk versi canon, ISO dan Diafragma (F) adalah optional tergantung cahaya alami dan background yang ada. Saat ingin mendapatkan fokus yang tajam dan akurat namun background 
blur maka F diturunkan menjadi F 1.2 atau 1.8. Sebaliknya jika konsep yang dibutuhkan adalah fokus penuh maka $\mathrm{F}$ dinaikkan menjadi 3 atau 4. Tim pengabdian tidak hanya mengambil 1 pengambilan gambar namun beberapa yang bertujuan untuk stock jika video pertama mungkin ada kesalahan dan mood dari model sedang tidak baik. Di samping itu, tim pengabdian menyiapkan lampu yang berguna untuk fill light karna key lightnya adalah cahaya matahari supaya terkesan mempunyai dimensi.

\section{PASCA PRODUKSI}

Proses terakhir pelaksanaan pengabdian adalah dilakukan Pengeditan untuk konten video. Bagian pertama yaitu seleksi footage video, kemudian penyusunan footage video, lalu diberi backsound dan melakukan pewarnaan pada footage video agar terkesan mempunyai cerita. Berikutnya, meletakkan effect seperti masking dan deep to black. Selanjutnya, video diperlihatkan kepada Lori untuk meminta saran. Jika ada yang perlu diperbaiki, maka akan mulai revisi bagian-bagian mana dari video yang menurutnya itu kurang. Revisi akan terus dilakukan sampai owner menyetujui videonya.

\section{Video Profile}

Konten Video yang dibuat berupa video profile dari Lori Collection agar dapat terlihat secara keseluruhan dalam tampilan profile. Menurut Irfan "Video company profile salah satu media efektif dalam mempropagandakan perusahaan, produk, hinga promosi untuk potensi suatu daerah"'[8]. Berawal dari mendaftarkan Lori Collection ke event Jogja Premium Ekspor Virtual Expo 2020 yang diadakan pada tanggal 12 sampai 15 November 2020. Pameran yang diselenggarakan oleh Dinas Perindustrian dan Perdagangan Daerah Istimewa Yogyakarta (DIY) ini memberikan peluang kepada para pelaku usaha untuk melakukan promosi dan menunjukkan potensi UMKM untuk bersaing di kancah Internasional. Sebelum itu, Lori Collection mendapat pemberitahuan untuk menghadiri Technical Meeting yang diselenggarakan pada tanggal 27 Oktober 2020. Lori Collection sebagai Peserta mendapat penjelasan mengenai diharuskan untuk mengumpulkan video yang akan dipost di Virtual Expo pada tanggal 1 November 2020.

Gambar 1 menunjukkan dokumentasi Technical Meeting. Proses pengambilan gambar dan editing dilakukan setelah Technical Meeting mengumumkan tentang prosedur pembuatan video.

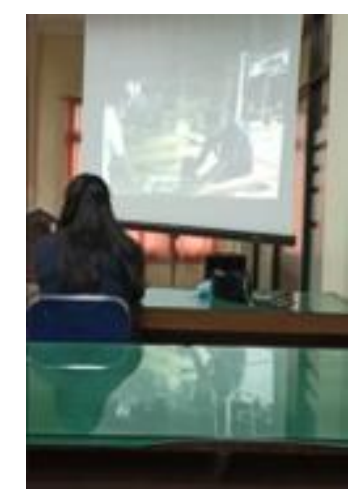

Gambar 1. Technical Meeting

Mitra mempersiapkan produk-produk yang akan diambil untuk konten video, kemudian mempersiapkan produk yang akan dipakai oleh model. Berikutnya, pengambilan video pun 
Gambar 2 dan 3.

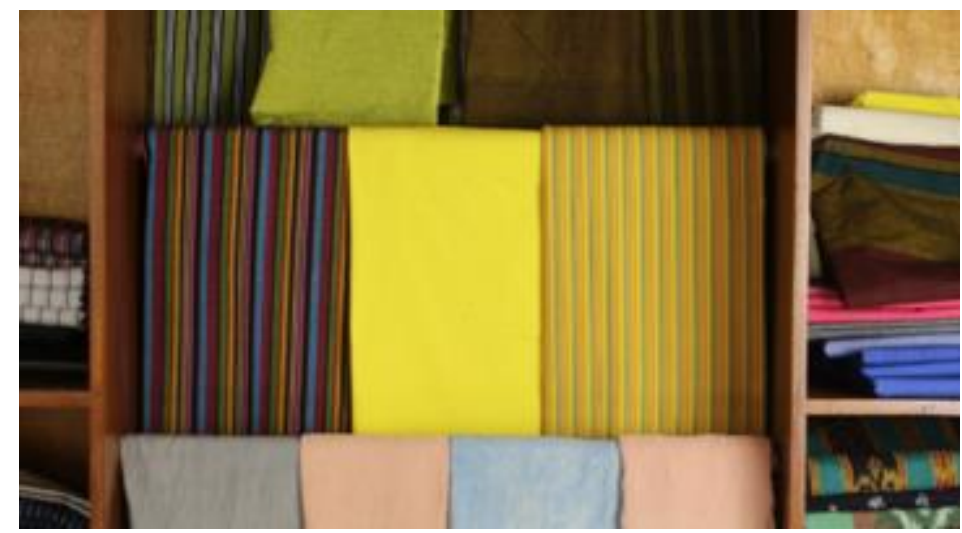

Gambar 2. Dokumentasi produk-produk yang akan diambil untuk Konten Video Profile

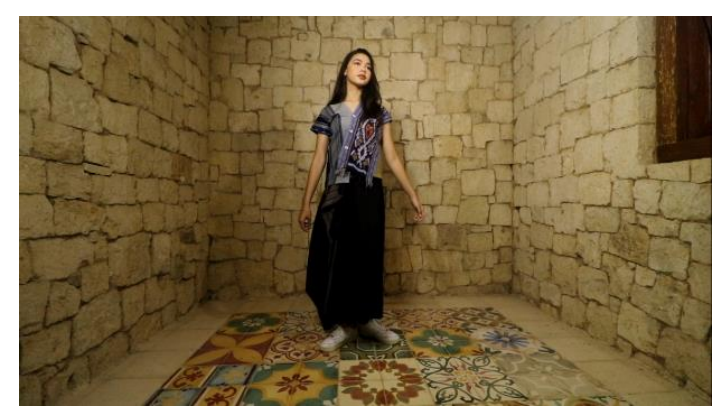

Gambar 3. Dokumentasi Produk yang dipakai oleh model

Setelah pengambilan video selesai, beralih ke proses editing video. Konten video tersebut satu-per satu digabungkan, kemudian diedit menggunakan tools video editor. Proses editing video ditampilkan pada Gambar 4. Pemilihan video dilakukan setelah mendapat rekomendasi dari mitra. Kemudian penambahan efek dan penggabungan menjadi sebuah video profile untuk ditampilkan ke Event Virtual.

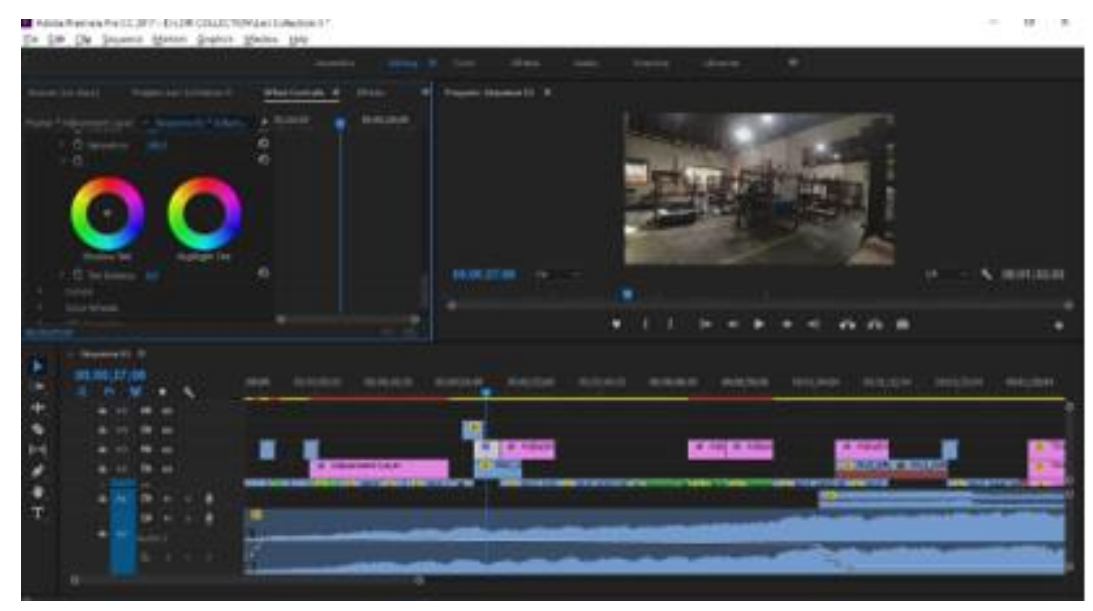

Gambar 4. Dokumentasi Proses Editing Konten Video Profile 
Setelah video profile diedit, dajukan kembali ke mitra apakah telah memenuhi kriteria video yang diinginkan. Mitra memberi revisi pada video profile yaitu saat model tampil, prioritas utama menampilkan baju luriknya. Video disunting kembali, lalu diajukan kembali ke mitra. Setelah mitra menyetujui, kemudian dikirim ke bagian pendaftaran sebuah event virtual Expo.

\section{Peningkatan Keberdayaan Mitra setelah kegiatan pengabdian}

Lori Collection saat ini menjadi salah satu UMKM binaan DISPERINDAG DIY. Sebagai salah satu binaan, Lori diundang untuk mengikuti kurasi produk. Jika Produk lolos kurasi, maka akan diikutkan pada virtual expo produk-produk export mewakili Jogja untuk bidang fashion. Dari sekian banyak UMKM binaan, hanya 2 UMKM yang lolos kurasi dan salah satunya adalah Lori. Untuk mengikuti Expo tersebut, UMKM diminta untuk menampilkan produknya dalam bentuk digital baik berupa video profil maupun katalog digital.

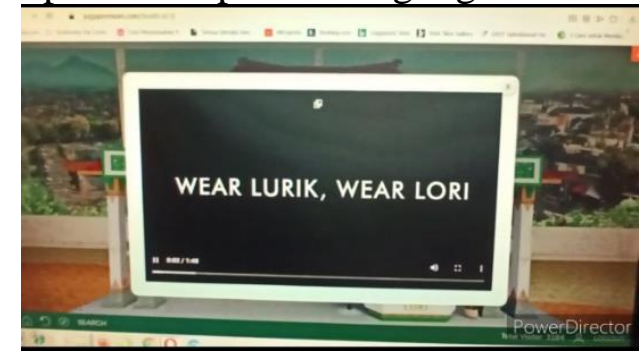

Gambar 5. Konten Video Profile

Selan itu, Lori Collection mendapatkan undangan untuk mengikuti UMKM Ekspor Brilian Preneur 2020. Selain itu beberapa video juga didiseminasikan di media social Lori seperti Instagram (https://www.instagram.com/lori.wardrobe/) dan facebook (https://www.facebook.com/loribydinarosaria) serta website official lori (http://wearlori.com)

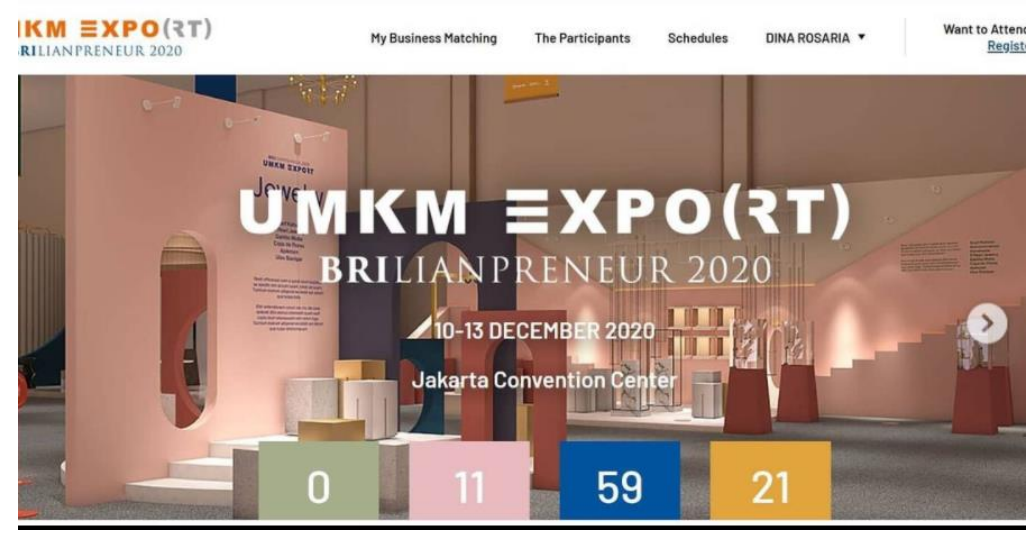

Gambar 6. UMKM Ekspor Brilian Preneur2020.

Video Lori Collection tidak hanya ditampilkan dalam Virtual Expo dan UMKM Export Brilianpreneur, namun juga diposting di media sosial Lori seperti Instagram dan Facebook. Setelah konten video diposting dan dikenai paid promote Instagram, terdapat kenaikan impresi menjadi 84.813, 3.899 kunjungan profil, 272 klik pada situs web, dan 15 klik pada tombol "Get Direction". Tampilan Reach Instagram ini dapat dilihat pada Gambar 7. Sayangnya, tidak ada dokumentasi/record impresi sebelum pemasangan iklan video pada media sosial tersebut, namun menurut penuturan dari pemilik UMKM, terjadi kenaikan yang cukup signifikan dari sebelum posting iklan dengan konten video dari hasil pengabdian dengan sesudah posting. 


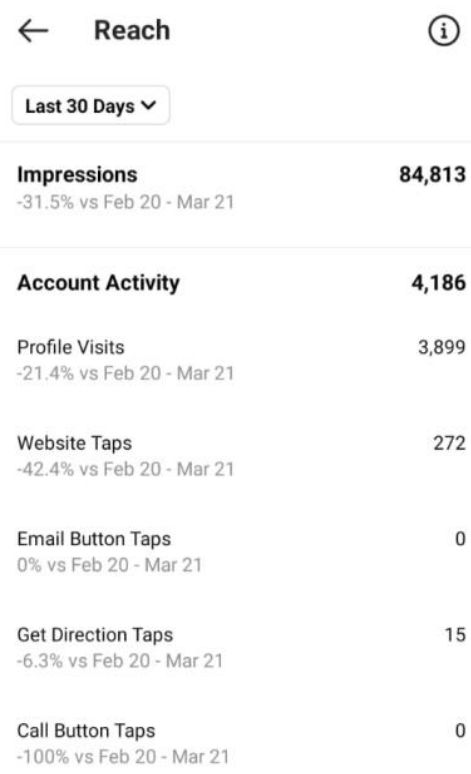

Gambar 7. Reach Instagram Lori Collection setelah posting iklan dengan Konten Video

\section{Simpulan}

Kegiatan Pendampingan dan Pembuatan Konten Video untuk Mendukung Pemasaran melalui Media Sosial Bagi UMKM Fashion telah membuahkan beberapa manfaat dan keberdayaan. Manfaat yang dirasakan antara lain yang pertama, terbangunnya brand image Lori Collection di dunia maya. Hal ini akan menambah lingkup eksistensi dari UMKM. Tidak hanya dikenal secara offline. Namun juga dikenal secara online. Hal ini dapat memperluas pasar dari UMKM Lori Collection. Kedua, kemudahan untuk melakukan promosi karena bisa dilakukan dimana saja dan kapan saja asalkan terhubung dengan internet dan memiliki gadget untuk melakukan pembuatan konten video serta memposting di sosial media. Hal ini membuat biaya yang dikeluarkan cenderung lebih murah dan mendapat hasil yang lebih baik dibandingkan dengan promosi biasa yang sebelumnya dilakukan yaitu dengan memposting foto di web resmi maupun di sosial media. Ketiga, variasi promosi via sosial media yang dapat bertahan sampai kapanpun kecuali post telah dihapus. Selain itu, peningkatan keberdayaan yang dirasakan oleh Lori adalah, terpilihnya Lori menjadi salah satu UMKM binaan Disperindag DIY, tampilnya Lori dalam UMKM Expo Brilianpreneur, dan meningkatnya reach pada sosial media Lori. Keterbatasan dalam pengabdian ini adalah kurangnya fasilitas pendukung seperti perangkat komputer untuk rendering, ketersediaan kamera untuk recording video dan software editing. Sehingga pelatihan mitra UMKM untuk dapat memproduksi video secara keberlanjutan mengalami hambatan. Selanjutnya, untuk rencana kegiatan pengabdian selanjutnya, dapat dilakukan sosialisasi tentang strategi promosi media social pada Lori Collection dan pelatihan pembuatan konten video sederhana bagi pelaku UMKM agar dapat menghasilkan konten video yang menarik dan dapat dijadikan konten pemasaran. 


\section{Daftar Pustaka}

Boman, K., \& Raijonkari, K. (2017). Online Video as a Marketing Tool A Quantitative Survey on Video Marketing Habits. Degree Programme in Music and Media Management, (Boman, K., Raijonkari, K. (2017). Online Video as a Marketing Tool A quantitative survey on video marketing habits.).

Brown, J. S., Prusak, L., Denning, S., \& Groh, K. (2005). Storytelling in organizations: Why storytelling is transforming 21st century organizations and management. Burlington: Elsevier Butterworth-Heinemann.

Handoko, H., Simanjorang, Monika Irene; Stephani, L., \& Yudistira, Gusti Bagus; Primasari, C. H. (2019). Dampak iklan di media sosial terhadap minat pembelian mahasiswa. Proceeding sintak 2019. Semarang: universitas stikubank.

Irfan, M. (2013). Pembuatan Video Company Profil Pada Belukar Merch di Kelurahan Jayengan Kecamatan Serengan Kota Surakarta. Seminar Riset Unggulan Nasional Informatika Dan Komputer FTI UNSA, 2(1), 50-54.

Jafar, A., \& Wahyuni. (2016). Pengaruh Hard Skill Dan Soft Skill Terhadap Kinerja Pegawai Pada Dinas Pendidikan Provinsi Sulawesi Selatan. Jurnal Ekonomi Dan Bisnis Islam.

Kee, A. W. A., \& Yazdanifard, R. (2015). The Review of Content Marketing as a New Trend in Marketing Practices. International Journal of Management, Accounting and Economics.

Kementrian Perindustrian. (2019). Industri Pakaian Jadi Catatkan Pertumbuhan Paling Tinggi. Retrieved from https://kemenperin.go.id/artikel/20641/Industri-Pakaian-Jadi-CatatkanPertumbuhan-Paling-Tinggi

Odden, L. (2013). Engaging more influencers and buyers with content marketing. Public Relation Tactics.

Primasari, Clara Hetty; Wibisono, Yohanes Priadi; Padawangi, T. Q. (2020). Social media marketing sebagai sarana peningkatan kualitas pemasaran komunitas umkm paroki st. Antonius kotabaru yogyakarta. Ikra-ith abdimas, 3(3). https://doi.org/10.37817/ikraithabdimas.v3i3

Schwarzl, S., \& Grabowska, M. (2015). Online marketing strategies: the future is here. Journal of International Studies, 8(2).

Setiawan, Andreas Gilbert Sesilia, O. (2019). Trend industri fesyen di indonesia. Retrieved from https://binus.ac.id/bandung/2019/12/trend-industri-fesyen-di-indonesia/

Zulkifli, Rasid, B., Tewal, C., \& Kojo. (2018). Pengaruh hard skill dan soft skill terhadap kinerja karyawan perum damri manado. Jurnal emba: Jurnal Riset Ekonomi, Manajemen, Bisnis Dan Akuntansi. https://doi.org/10.35794/emba.v6i2.20030 